\title{
HUBUNGAN KECERDASAN EMOSIONAL DENGAN DERAJAT HIPERTENSI PADA LANSIA DI PUSKESMAS RANOTANA WERU
}

\author{
Muhamad Nurmansyah \\ Rina Kundre \\ Program Studi Ilmu Keperawatan Fakultas Kedokteran \\ Univeristas Sam Ratulangi \\ Email : muhamad.nurmansyah@unsrat.ac.id
}

\begin{abstract}
Abstrack Hypertension is a condition where a person experiences a rise in blood pressure either slowly or suddenly. Hypertension sufferers are currently experiencing an increase, especially in the age stage of the elderly. One of the factors that influence hypertension is difficulty in controlling emotions, which can increase the levels of adrenaline hormone which results in increased blood pressure. The purpose was to identify the relationship of emotional intelligence with hypertension degrees in the elderly. The design study is cross sectional. Samples is 69 respondents with a purposive sampling technique. Data collection uses a questionnaire consisting of 30 questions and observation sheets. Results used Chi Square test with $95 \%$ significance level obtained a significant value of $p=0.003$ or smaller than 0.05. Conclusion there is a relationship between emotional intelligence and hypertension degrees in the elderly at public health center of Ranotana Weru .
\end{abstract}

Keywords: Hipertertension, Emotional inteligence and hipertension degrees

\begin{abstract}
Abstrak : Hipertensi merupakan suatu kondisi dimana seseorang mengalami kenaikan tekanan darah baik secara lambat maupun mendadak. Penderita hipertensi saat ini mengalami peningkatan, apalagi pada tahap usia lansia. Salah satu faktor yang mempengaruhi hipertensi adalah kesulitan dalam mengendalikan emosi, di mana dapat meningkatkan kadar hormone adrenalin yang emngakibatkan tekanan darah meningkat. Tujuan untuk mengetahui hubungan kecerdasan emosional dengan derajat hipertensi pada lansia. Metode penelitian menggunakan cross sectional. Teknik sampling dalam penelitian ini adalah purposive sampling, yang terdiri dari 69 responden. Pengumpulan data menggunakan kuesioner yang terdiri dari 30 pertanyaan dan lembar observasi . Hasil penelitian dengan menggunakan uji Chi Square pada tingkat kemaknaan $95 \%$ diperoleh nilai signifikan $p=0.003$ atau lebih kecil dari 0.05. Kesimpulan ada hubungan kecerdasan emosional dengan derajat hipertensi pada lansia di Puskesmas Ranotana Weru.
\end{abstract}

Kata Kunci : Hipertensi, Kecerdasan Emosional, Derajat Hipertensi 


\section{PENDAHULUAN}

Penyakit hipertensi atau yang sering disebut dengan penyakit "darah tinggi" merupakan suatu kondisi dimana seseorang mengalami kenaikan tekanan darah baik secara lambat maupun mendadak (Agoes, 2011).Hipertensi atau tekanan darah tinggi merupakan masalah kesehatan yang terjadi di seluruh dunia. Berdasarkan data tahun 2013, menyatakan bahwa terjadi peningkatan jumlah orang yang menderita hipertensi dari 600 juta pada tahun 1980 menjadi 1 milyar pada tahun 2008. (Kemenkes RI, 2014).

Prevalensi Hipertensi nasional berdasarkan Riskesdas 2013 sebesar 25,8\%, tertinggi di Kepulauan Bangka Belitung (30,9\%), sedangkan terendah di Papua sebesar (16,8\%). Riskesdas 2018 menunjukkan prevalensi Penyakit Tidak Menular mengalami kenaikan jika dibandingkan dengan Riskesdas 2013, antara lain kanker, stroke, penyakit ginjal kronis, diabetes melitus, dan hipertensi,

hasil pengukuran tekanan darah, hipertensi naik dari 25,8\% menjadi 34,1\%. Menurut Badan Pusat Statistik Kota Manado, pravelensi hipertensi pada tahun 2011 mencapai,11.196 kasus dan terjadi kenaikan kasus hipertensi dari tahun ke tahun hingga data terakhir yang didapat pada tahun 2015 di Manado terdapat 16.524 kasus.

Hipertensi merupakan penyebab utama penyakit kardiovaskuler dan

merupakan kondisi kronis yang berkontribusi utama pada penyakit lain dan disabilitas. Prevalensi hipertensi yang tinggi pada orang dewasa berusia $\geq 25$ tahun dengan tertinggi pada negara berpenghasilan rendah. Penyakit ini dapat menyebabkan perubahan pada pembuluh darah hingga berdampak pada Hypothalamic Pituitary Adrenal (HPA) yang menstimulus korteks adrenal untuk melepaskan kortisol menuntut hipotalamus dan amigdala di dalamnya sebagai pengatur kecerdasan emosional (EI) yang mengarah pada potensial kearah lebih sensitif seperti amarah. Perubahan
EI ini dapat mempengaruhi sudut pandang, pengalaman, dan koping pada pengalaman stres psikologis yang dapat berhubungan dengan kualitas hidup pasien hipertensi. (Sutanto,2015).

Gaya hidup negatif dapat dipengaruhi oleh pola pikir yang kurang baik misalnya karena beban dalam pikiran yang menumpuk dan mekanisme koping yang kurang baik sehingga lama kelamaan mengakibatkan stress. Stress atau

ketegangan emosional dapat mempengaruhi sistem kardiovaskuler.

Secara psikologis stress dapat meningkatkan tekanan darah, oleh sebab itu penderita hipertensi harus mampu mengendalikan emosi (Marliani, 2007). Berdasarkan hasil penelitian dari Andria 2013, menunjukkan bahwa sebagian besar lansia yang hipertensi termasuk dalam kriteria tidak mampu beradaptasi, akibat dari ketidakmampuan tersebut sehingga diperlukan cara untuk mampu beradaptasi terhadap stress salah satu cara yang dapat dilakukan yaitu dengan kecerdasan emosional yang baik. Dalam kehidupan

sehari-hari seperti bermasyarakat, pengendalian emosi sangat penting karena dapat menciptakan kehidupan yang lebih harmonis dan nyaman sehingga dapat meminimalkan stress diakibatkan oleh beban pikiran dan emosi yang tidak terkontrol. Kecerdasan emosional sangat berpengaruh dalam semua aspek kehidupan mulai dari keluarga, pekerjaan, sampai interaksi dengan lingkungan sosial (Notoatmodjo, 2012).

Lima dimensi kecerdasan emosional menurut Goleman (2005) yaitu meliputi mengetahui emosi dalam diri sendiri, mengatur emosi diri sendiri, dapat memotivasi diri sendiri, dapat mendukung dan memahami emosi orang lain, dan membina hubungan dengan orang lain. Berdasarkan pendataan awal oleh peneliti pada bulan Januari yang didapatkan dari Puskesmas Ranotana Weru, diperoleh data penderita hipertensi pada lansia berjumlah 263 orang. Dibagi dalam kategori usia pertengahan (45-59 tahun) 152 orang,usia 
lanjut (60-74 tahun) 63 orang, usia tua ( $>75$ tahun) 48 orang . Dari hasil wawancara yang dilakukan pada 5 orang lansia diperoleh 2 orang lansia mampu memenuhi 5 aspek kecerdasan emosional dan 3 orang lainnya hanya memenuhi 4 aspek kecerdasan emosional. Aspek yang tidak terpenuhi adalah kemampuan mengelolah emosi. Berdasarkan urian diatas membuat peneliti tertarik untuk meneliti tentang "Hubungan Kecerdasan Emosional dengan Derajat Hipertensi pada Lansia di Puskesmas Ranotana Weru Manado".

\section{METODE PENELITIAN}

Penelitian ini termasuk dalam jenis penelitian kuantitatif dengan menggunakan metode penelitian survei analitik untuk menganalisis hubungan antara 2 variabel yaitu variabel independen (kecerdasan emosional) dan variabel dependen (derajat hipertensi).

Penelitian ini menggunakan desain penelitian cross sectional (Notoatmodjo, 2012). Penelitian ini dilaksanakan di Puskesmas Ranotana Weru pada bulan Februari- Maret 2019. Populasi penelitian ini adalah 150 lansia hipertensi. Pengambilan sampel menggunakan teknik purposive sampling (Notoatmodjo, 2012) maka didapatkan jumlah sampel minimal 69. Instrument penelitian yang digunakan untuk mengukur variabel kecerdasan emosional menggunakan kuesioner yang pernah digunakan sebelumnya oleh Wiska (2014) yang telah diuji validitasnya. Kuesioner yang digunakan dalam penelitian ini terdiri dari 30 pertanyaan. menggunakan skala Likert dengan skor dan pilihan 1: sangat tidak setuju, 2: tidak setuju, 3: setuju, 4: sangat setuju.

Penilaian kecerdasan emosional dilakukan dengan menggunakan Cut Of Point caranya yaitu dengan nilai uji normalitas data dan didapatkan hasil mean

81. Selanjutnya di kategorikan kecerdasan emosional baik dengan nilai $\geq 81$ dan kecerdasan emosional tidak baik $<81$.
Pengukuran untuk variabel derajat hipertensi menggunakan lembar observasi yang didalamnya terdiri karakteristik

responden (Umur,jenis kelamin,dan pendidikan) dan tabel observasi yang terdiri dari nomor,tanggal pemeriksaan dan tekanan darah. Pengolahan data yang diperoleh dari hasil penelitian ini diolah secara manual dengan mengelompokan hasil kuesioner dan observasi kemudian dilakukan penghitungan skor setelah itu dianalisis menggunakan uji statistik

melalui sistem komuterisasi dengan beberapa tahap yaitu editing, coding, transfering, tabulating (Notoatmodjo, 2012). Analisa bivariat dalam penelitian ini yaitu untuk mengetahui hubungan kecerdasan emosional dengan derajat hipertensi pada lansia di Puskesmas Ranotana Weru. Peneliti menggunakan uji Chi - square pada tingkat kemaknaan 95\% (P.Value < 0,05) (Notoatmodjo, 2012).

\section{HASIL dan PEMBAHASAN}

\section{Karakteristik Responden}

Tabel 1. Distribusi Responden Berdasarkan Usia

\begin{tabular}{ccc}
\hline Umur & $\mathbf{N}$ & $\mathbf{\%}$ \\
\hline 45-59 Tahun & 18 & 26,1 \\
60-74 Tahun & 41 & 59,4 \\
75-90 Tahun & 10 & 14,5 \\
\hline Total & $\mathbf{6 9}$ & $\mathbf{1 0 0}$ \\
\hline
\end{tabular}

Sumber : Data Primer 2019

Distribusi responden dilihat dari karakteristik berdasarkan usia, menunjukan bahwa terbanyak adalah usia 60-74 tahun $(59,4 \%)$. Hasil penelitian ini sesuai dengan dengan penelitian yang dilakukan Hazwan (2017), menunjukkan usia yang paling banyak mengalami hipertensi yaitu >50 tahun. Hal ini dikarenakan pada usia tua terjadi perubahan struktural dan fungsional pada sistem pembuluh darah arteri dan perifer yaitu kehilangan kelenturan dan elastisitas sehingga pembuluh darah arteri menjadi kaku dan akhirnya mempengaruhi perubahan tekanan darah di usia tua. 
Tabel 2. Distribusi Responden Berdasarkan Jenis Kelamin

\begin{tabular}{ccc}
\hline Jenis Kelamin & n & \% \\
\hline Laki-laki & 32 & 46,4 \\
Perempuan & 37 & 53,6 \\
\hline Total & $\mathbf{6 9}$ & $\mathbf{1 0 0}$ \\
\hline
\end{tabular}

Sumber : Data Primer 2019

Berdasarkan Jenis kelamin, diperoleh sebagian besar responden memiliki jenis kelamin perempuan $(53,6 \%)$. Hasil penelitian Hasil penelitian ini sejalan dengan Karim (2018) dimana dari 40 responden 27 diantaranya perempuan. Jenis kelamin perempuan sangat erat kaitannya dengan kejadian hipertensi terutama pada perempuan yang mengalami manopause dimana ketika seorang perempuan mengalami manopause, terjadi penurunan hormon esterogen yang berperan melindungi pembuluh darah dari kerusakan (Kusumawaty, 2016).

Tabel 3. Distribusi Responden Berdasarkan Pendidikan

\begin{tabular}{ccc}
\hline Jenis & n & \% \\
\hline SD & 13 & 18,8 \\
SMP & 29 & 42,0 \\
SMA & 24 & 34,8 \\
S1 & 3 & 4,3 \\
\hline Total & $\mathbf{6 9}$ & $\mathbf{1 0 0}$ \\
\hline
\end{tabular}

Sumber : Data Primer 2019

Penelitian ini didapatkan sebagian responden memiliki Pendidikan SMP yaiu sebanyak 29 orang $(42,0 \%)$.Hasil penelitian ini sejalan dengan Ulfiyah (2013) pada penelitian tentang Hubungan antara tingkat pengetahuan dengan perilaku wanita menopause dalam upaya pencegahan penyakit Gout di kelurahan Pisangan didapatkan dari 76 responden 36 diantaranya SMP. Perry dan Potter (2005), menyatakan bahwa pendidikan sangat berpengaruh terhadap tingkat pengetahuan seseorang. Semakin tinggi pendidikan

seseorang, maka wawasan yang dimilikinya akan semakin luas sehingga pengetahuan pun akan meningkat. Sebaliknya semakin rendah pendidikan seseorang maka wawasan yang dimiliki akan semakin sempit sehingga menurunkan tingkat pengetahuan. Hasil penelitian ini juga di dukung oleh Waas, dkk (2014) di mana responden yang memilki tingkat pendidikan rendah dan menengah memiliki resiko 2,9 kali menderita hipertensi di bandingkan dengan responden yang berpendidikan tinggi.

\section{Analisa Univairat}

Tabel 4. Distribusi Responden Berdasarkan Kecerdasan Emosional

\begin{tabular}{ccc}
\hline $\begin{array}{c}\text { Kecerdasan } \\
\text { Emosional }\end{array}$ & n & \% \\
\hline Baik & 39 & 56,5 \\
Kurang baik & 30 & 43,5 \\
\hline Total & $\mathbf{6 9}$ & $\mathbf{1 0 0}$ \\
\hline
\end{tabular}

Sumber : Data Primer 2019

Berdasarkan hasil penelitian di Puskesmas Ranotana Weru diperoleh kecerdasan emosional paling banyak baik dengan jumlah 39 (56,5\%).Emosi merupakan salah satu aspek yang sangat penting dalam kehidupan manusia, karena emosi merupakan hal yang menjadi penyimbang dalam setiap mengambil keputusan. Istilah kecerdasan emosional pertama kali dilontarkan pada tahun 1990 oleh psikolog Peter Salovey dari Harward University dan John Mayr dari University of New Hampshire, beberapa bentuk kualitas emosional yang dinilai penting bagi keberhasilan (Aunurrahman, 2016).

Tabel 4 menunjukan penelitian ini responden lebih dominan memiliki kategori kecerdasan emosional baik.

Orang yang memiliki kecerdsan emosional baik memilki ciri-ciri diantaranya tidak takut pada perubahan ,punya empati,mereka tahu kekuatan dan kelemahan diri serta mampu memotivasi diri sendiri (Totik,2017). 
Tabel 5. Disitribusi Responden Berdasarkan Derajat Hipertensi

\begin{tabular}{ccc}
\hline $\begin{array}{c}\text { Derajat } \\
\text { Hipertensi }\end{array}$ & N & \% \\
\hline Derajat I & 39 & 56,5 \\
Derajat II & 14 & 20,3 \\
Derajat III & 16 & 23,2 \\
\hline Total & $\mathbf{6 9}$ & $\mathbf{1 0 0}$ \\
\hline
\end{tabular}

Sumber : Data Primer 2019

Data pada tabel 5 diatas tentang derajat hipertensi menunjukan bahwa responden paling banyak adalah derajat I sebanyak 39 orang $(56,5 \%)$, sedangkan derajat III sebanyak 16 orang $(20,3 \%)$ dan derajat II sebanyak 14 orang $(23,2 \%)$. Hasil ini sejalan dengan penelitian Rahmadesi (2016) didapatkan 50 responden, 29 orang $(58 \%)$ diantaranya menderita hipertensi derajat I. Beberapa faktor yang berhubungan dengan derajat hipertensi yaitu faktor keturunan, obesitas, stress, kebiasaan merokok, konsumsi alkohol dan kopi. Beberapa aspek social yang mempengaruhi status kesehatan seseorang, antar lain adalah: umur, jenis kelamin, pekerjaan dan social ekonomi. Artinya keempat aspek social tersebut dapat mempengaruhi status kesehatan responden salah satunya adalah derajat hipertensinya (Notoatmodjo,2007).

\section{Analisa Bivariat}

Tabel 5. Hubungan Kecerdasan Emosional Dengan Derajat Hipertensi Pada Lansia

\begin{tabular}{cccccccccc}
\hline Kecerdasan & \multicolumn{7}{c}{ Derajat hipertensi } \\
\cline { 2 - 8 } emosional & Derajat 1 & Derajat 2 & Derajat 3 & Jumlah & $\begin{array}{c}\text { P- } \\
\text { value }\end{array}$ \\
\cline { 2 - 9 } & $\mathrm{n}$ & $\%$ & $\mathrm{n}$ & $\%$ & $\mathrm{n}$ & $\%$ & $\mathrm{n}$ & $\%$ & \\
\hline Baik & 23 & 59 & 11 & 28 & 5 & 13 & 39 & 100 & \\
Kurang & 16 & 53 & 3 & 10 & 11 & 37 & 30 & 100 & \\
baik & & & & & & & & & \\
\hline Total & $\mathbf{3 9}$ & $\mathbf{5 6}$ & $\mathbf{1 4}$ & $\mathbf{2 1}$ & $\mathbf{1 6}$ & $\mathbf{2 3}$ & $\mathbf{6 9}$ & $\mathbf{1 0 0}$ & \\
\hline
\end{tabular}

Sumber : Data Primer 2019

Hasil uji Chi- Square hubungan kecerdasan emosional dengan derajat hipertensi di Puskesmas Ranotana Weru tahun 2019 di peroleh hasil $p$ value 0,030 dimana menunjukkan bahwa terdapat hubungan kecerdasan emosional dengan derajat hipertensi pada lansia di Puskesmas Ranotana Weru tahun 2019. Sejalan dengan penelitian Rahmadesi (2016) bahwa terdapat hubungan antara kecerdasan emosional dengan derajat hipertensi pada lansia di desa Tanjung Sari Kecamatan Pacitan.

Penyakit ini dapat menyebabkan perubahan pada pembuluh darah hingga berdampak pada Hypothalamic Pituitary Adrenal (HPA) terhadap pelepasan kortisol oleh korteks adrenaldan menuntut hipotalamus dan amigdala di dalamnya sebagai pengatur kecerdasan emosional (EI) yang mengarah pada potensial kearah lebih sensitif seperti amarah. Perubahan EI ini dapat mempengaruhi sudut pandang, pengalaman, dan koping pada pengalaman stres psikologis yang dapat berhubungan dengan kualitas hidup pasien hipertensi. (Sutanto,2015). Gaya hidup negative dapat dipengaruhi oleh pola pikir yang kurang baik misalnya karena beban dalam pikiran yang menumpuk dan mekanisme koping yang kurang baik sehingga lama kelamaan mengakibatkan stress. Stress atau ketegangan emosional

dapat mempengaruhi system kardiovaskuler. Secara psikologis stress dapat meningkatkan tekanan darah, oleh sebab itu penderita hipertensi harus mampu mengendalikan emosi (Marliani, 2007). Salah satu faktor yang mempengaruhi hipertensi adalah stress (Bell,et,al,2015).

Berdasarkan hasil penelitian dari Andria 2013,menunjukkan bahwa sebagian besar lansia yang hipertensi termasuk dalam kriteria tidak mampu beradaptasi,akibat dari ketidakmampuan tersebut sehingga diperlukan cara untuk mampu beradaptasi terhadap stress. Sedangkan menurut Agustian (2007)

faktor-faktor yang mempengaruhi kecerdasan emosional, yaitu: Faktor psikologis, merupakan faktor yang berasal dari dalam diri individu. Faktor internal ini akan membantu individu dalam mengelola, mengontrol, mengendalikan 
dan mengkoordinasikan keadaan emosi agar termanifestasi dalam perilaku secara efektif. Menurut Goleman (2007) kecerdasan emosi erat kaitannya dengan keadaan otak emosional. Bagian otak yang mengurusi emosi adalah sistem limbik. Sistem limbik terletak jauh dalam hemisfer otak besar dan terutama bertanggung jawab atas pengaturan emosi dan impuls. Peningkatan kecerdasan emosi secara fisiologis dapat dilakukan dengan puasa. Puasa tidak hanya

mengendalikan dorongan fisiologis manusia, namun juga mampu mengendalikan kekuasaan impuls emosi. Puasa yang dimaksud salah satunya yaitu puasa sunah Senin Kamis.

Faktor pelatihan emosi, kegiatan yang dilakukan secara berulang-ulang akan menciptakan kebiasaan, dan

kebiasaan rutin tersebut akan menghasilkan pengalaman yang berujung pada pembentukan nilai (value). Reaksi emosional apabila diulang-ulang pun akan berkembang menjadi suatu kebiasaan. Pengendalian diri tidak muncul begitu saja tanpa dilatih. Melalui puasa sunah Senin Kamis, dorongan, keinginan, maupun reaksi emosional yang negatif dilatih agar tidak dilampiaskan begitu saja sehingga mampu menjaga tujuan dari puasa itu sendiri. Kejernihan hati yang terbentuk melalui puasa sunah Senin Kamis akan menghadirkan suara hati yang jernih sebagai landasan penting bagi pembangunan kecerdasan emosi. Faktor pendidikan, dapat menjadi salah satu

sarana belajar individu untuk mengembangkan kecerdasan emosi. Individu mulai dikenalkan dengan berbagai bentuk emosi dan bagaimana mengelolanya melalui pendidikan. Pendidikan tidak hanya berlangsung di sekolah, tetapi juga di lingkungan keluarga dan masyarakat. Sistem pendidikan di sekolah tidak boleh hanya menekankan pada kecerdasan akademik saja, memisahkan kehidupan dunia dan akhirat, serta menjadikan ajaran agama sebagai ritual saja. Pelaksanaan puasa sunah Senin Kamis yang berulang-ulang dapat membentuk pengalaman keagamaan yang memunculkan kecerdasan emosi. Puasa sunah Senin Kamis mampu mendidik individu untuk memiliki kejujuran, komitmen, visi, kreativitas,

ketahanan mental, kebijaksanaan, keadilan, kepercayaan, peguasaan diri atau sinergi, sebagai bagian dari pondasi kecerdasan emosi. Agustian (2007)

Pemicu terjadinya peningkatan tekanan darah pada pasien hipertensi adalah stress. Stress merupakan suatu tanggapan atau reaksi tubuh terhadap berbagai tuntutan atau beban yang bersifat non spesifik. Stress ini juga bisa menjadi faktor pencetus dan penyebab dari suatu gangguan atau penyakit. Dalam kondisi ini faktor-faktor psikologis mempunyai cukup peran bagi terjadinya stress pada diri seseorang serta dapat meningkatkan tekanan darah, maka dari itu penderita hipertensi harus mampu mengendalikan emosinya (Marliani, 2007). Dalam penelitian ini ,di lihat dari jawaban yang diberikan responden dalam kuesioner kecerdasan emosional tergambar bahwa seseorang yang memiliki kecerdasan emosional baik, mampu mengendalikan emosi, mampu mengatasi stress, mampu mengekspresikan emosi lewat kata-kata, mampu beradaptasi dengan lingkungan baru, bisa berhubungan baik dengan orang lain, sehingga peneliti berasumsi semakin baik kecerdasan seserang maka berpengaruh pada derajat tekanan darah.

\section{SIMPULAN}

Berdasarkan hasil penelitian, maka di simpulkan bahwa terdapat hubungan kecerdasan emosional dengan derajat hipertensi pada lansia di Puskesmas Ranotana Weru. Mayoritas derajat hipertensi pada lansia di Puskesmas Ranotana Weru yaitu hipertensi derajat 1 . Hasil penelitian juga menunjukkan sebagian besar lansia hipertensi di Puskesmas Ranotana Weru memilki kecerdasan emosional yang baik . 


\section{DAFTAR PUSTAKA}

Agustian, A. G. (2007). Rahasia Sukses Membangun Kecerdasan Emosi dan Spiritual ESQ: Emotional Spiritual Quotient Berdasarkan 6 Rukun Iman dan 5 Rukun Islam. Jakarta: ARGA Publishing.

Agoes,H. A, (2011). Penyakit Diusia Tua. EGC: Jakarta

Andria, Kiki Melisa (2013). Hubungan antara perilaku olahraga, stress, dan pola makan dengan tingkat hipertensi pada lanjut usia di

Posyandu Lansia Kelurahan Gebang Putih kecamatan Sukolilo Kota Surabaya. Jurnal Promkes vol,1, No.2.

Aunurrahman (2016). Pelajar dan Pembelajaran ALFABETA, Bandung.

Badan Pusat Statistik: Kota Manado. (2015) Jumlah Kasus 10 jenis penyakit terbanyak di kota

Manado, 2011-2015. https://manadokota.bps.go.id/, diakses tanggal 14 November 2018

Bell $\mathrm{K}$, Twigss $\mathrm{J}$, Orlin BR (2015).

Hypertension: The Silent Killer. Updated JNC 8 Recommendation. Continuing Study. Auburn University. Alabama.

Goleman, Daniel (2005). Emotional Intellgance. New York: Bantam Dell.

Goleman, D. (2007). Kecerdasan Emosional: Mengapa EL lebih penting daripada IQ (Terjemahan T. Hermaya). Jakarta: Gramedia Pustaka Umum

Hazwan. Azri (2017). Gambaran karakteristik penderita hipertensi dan tingkat kepatuhan minum obat di wilayah kerja Puskesmas Kinatamani I.
Kusumawaty, Jajuk (2016). Hubungan jenis kelamin dengan intensitas hipertensi pads lansia di wilayah kerja Puskesmas Lakbok Kabupaten Ciamis. Program Studi Ners , STIKES Muhammadiyah Ciamis.

Karim,Nur Afni (2018). Hubungan aktivitas fisik dengan derajat hipertensi pada pasien rawat jaan di wilayah kerja Puskesmas Tagulandang Kabupaten Sitaro.

Kemenkes RI. (2014). INFODATIN HIPERTENSI. Jakarta Selatan: Pusat Data dan Informasi Kementrian Kesehatan RI .

Marliani, L, \& Tantan (2007). 100 Questions \& Answer Hipertensi. Jakarta: Elex.

Notoatmodjo, S. (2007). Promosi Kesehatan dan Ilmu Perilaku Kesehatan. Jakarta: Rineka Cipta

Notoatmodjo, S. (2012). Promosi Kesehatan dan Perilaku Kesehatan. Jakarta: Rineka Cipta.

Notoatmodjo, S. (2012). Metodologi penelitian kesehatan. Jakarta: Rineka Cipta.

Perry dan Potter (2005). Buku ajar Fundamental Keperawatan. Jakarta: EGC.

Rahmadesi, P, (2016). Hubungan Kecerdasan Emosional dengan Tingkat Hipertensi di Desa Tanjung Sari Kecamatan Pacitan. Program Studi S1 Keperawatan. Fakultas Ilmu Kesehatan Universitas Muhammadiya Surakarta.

Riset Kesehatan Dasar. (2013). Hasil Utama Riskesdas 2013. https://www.depkes.go.id 
e-journal Keperawatan(e-Kp) Volume 7 Nomor 1, 23 Juli 2019

Riset Kesehatan Dasar. (2018). Hasil

Utama Riskesdas 2018.

https://www.depkes.go.id

Sutanto, (2015). Hubungan antara kecerdasan emosional dengan kualitas tidur pasien hipertensi tahap II di Poliklinik Jantung Rumkit TK.II dr.SOEPRAOEN Malang. Fakultas Ilmu Kesehatan. Universitas Muhammadiyah Malang. http://eprints.umm.ac.id/23413/

Totik (2017). 10 Ciri-ciri orang dengan kecerdasan emosional yang tinggi. https://www.kompasiana.com/ma matotik/59d385ae7fd6e73c6265a4 73/10-ciri-orang-dengankecerdasan-emosional-yang$\underline{\text { tinggi?page }=\text { all }}$

Ulfiyah, Hamidatu (2013). Hubungan antara tingkat pengetahuan dengan perilaku wanita menopause dalam upaya pencegahan penyakit gout di Kelurahan Pisangan. Program studi Ilmu Keperawatan. Fakultas Kedokteran dan Ilmu Kesehatan UIN SYARIF HIDAYATULLA, Jakarta

Waas, F, Ratag, Budi, Umboh, Jootje (2014). Faktor-faktor yang berhubungan dengan kejadian hipertensi pada pasien rawat jalan Puskesmas Ratahan Kabupaten Minahasa Tenggara periode Desember 2013- Mei 2014. Fakultas Kesehatan Masyarakat Universitas Sam Ratulangi

Wiska, Nadia.(2014). Hubungan usia,jenis kelamin, masa studi, pengalaman praktikum dir rumah sakit dengan tingkat kecerdasan emosional mahasiswa tingkat akhir ilmu keperawatan. Fakultas Ilmu
Keperawatan

Indonesia. 